\title{
Determination of polyphenols in wines by reaction with 4-aminoantipyrine and photometric flow-injection analysis
}

\author{
Jan W. Schoonen • M. Goreti F. Sales
}

\begin{abstract}
A new flow-injection analytical procedure is proposed for the determination of the total amount of polyphenols in wines; the method is based on the forma- tion of a colored complex between 4-aminoantipyrine and phenols, in the presence of an oxidizing reagent. The oxidizing agents hexacyanoferrate(III), peroxodisulfate, and tetroxoiodate(VII) were tested.

Batch trials were first performed to select appropriate oxidizing agents, $\mathrm{pH}$, and concentration ratios of reagents, on the basis of their effect on the stability of the colored complex. Conditions selected as a result of these trials were implemented in a flow-injection analytical system in which the influence of injection volume, flow rate, and reaction-coil length, was evaluated. Under the optimum conditions the total amount of polyphenols, expressed as gallic acid, could be determined within a concentration range of 36 to $544 \mathrm{mg} \mathrm{L}^{-1}$, and with a sensitivity of $344 \mathrm{~L} \mathrm{~mol}^{-1} \mathrm{~cm}^{-1}$ and an RSD $<1.1 \%$. The reproducibility of analytical readings was indicative of standard deviations $<2 \%$. Interference from sugars, tartaric acid, ascorbic acid, methanol, ammonium sulfate, and potassium chloride was negligible.

The proposed system was applied to the determination of total polyphenols in red wines, and enabled analysis of approximately 55 samples $\mathrm{h}^{-1}$. Results were usually precise and accurate; the RSD was $<3.9 \%$ and relative errors, by the Folin-Ciocalteu method, $<5.1 \%$.
\end{abstract}

\section{Keywords}

Total polyphenols $\cdot$ Photometry $\cdot$ Wines $\cdot$ Flow injection and FIA

\section{Introduction}

Polyphenols are responsible for some of the organoleptic properties of wines - the intensity and type of color, the astringency and "hardness", the aroma, evolution and maturation with aging, etc. - and have both vitamin $\mathrm{P}$ and bactericide effects [1]. Although it is increasingly important to be able to recognize the different structures among this class of compounds and to determine their quantities, the establishment of a simple method that enables quantification of the total amount of polyphenols in wines is equally important.

Among the techniques used for this purpose, high-performance liquid chromatography is the most popular $[2,3$, $4,5]$. Because of the extreme complexity of matrices concerned, it is easy to understand the attractiveness of a separative technique, although when used for this purpose capacity is not fully exploited. The technique is also quite expensive when used routinely.

An alternative strategy used for quantitative analysis in recent decades is flow-injection analysis (FIA), which has several advantageous features, including versatility, simplicity, and low cost. The total amount of polyphenols in wines can also be determined by use of this concept. The first work proposed in the literature is an adaptation to flow conditions of the Jerumanis method [6] involving reaction with ammonium iron(III) citrate in alkaline medium, with formation of a colored iron(II)-polyphenol complex [7]. This procedure was, however, very dependent on the experimental conditions used for FIA; this resulted in errors up to $37 \%$ when results from flow and batch trials were compared.

This drawback was overcome by subsequent applications of FIA. Adaptation of the traditional Folin-Ciocalteu method [8] enabled the determination of, at least, 45 samples $\mathrm{h}^{-1}[9,10]$. This method is based on the reduction of a mixture of phosphotungstic and phosphomolybdic acids to tungsten and molybdenum oxides by phenols in basic media and, subsequent formation of a blue color, and gives rise to an index value always con- 

sidered to be conventional in nature. Although adapted by the Organization International du Vin (OIV, 1981), and still widely used, this method suffers from interference from several compounds, including ascorbic acid, reducing sugars, iron(II), nucleic acids, amino acids, and proteins [11]. Another disadvantage is that the color evolves with time, making it very difficult to obtain accurate results. Under the conditions used for FIA [9, 10] this last disadvantage is not of concern, because analytical readings are taken after a constant period of time. The same cannot, however, be said for chemical interferences with the Folin-Ciocalteu method.

The aim of this work was, therefore, the establishment of an alternative procedure with a different chemical background that would enable simple and more selective determination of total polyphenols. The method proposed is based on the oxidation of polyphenols and subsequent complexation with 4-aminoantipyrine, a reagent commonly used for the quantification of low levels of phenols in waters $[12,13]$. To enable determination of a large number of samples per hour, and to eliminate analytical errors arising as a result of the evolution of color with time, this principle was implemented in a FIA system.

\section{Experimental}

\section{Apparatus}

Spectrophotometric readings under batch conditions were made by means of a Shimadzu UV-2101 PC double-beam spectrophotometer and quartz cuvets with an optical path length of $10 \mathrm{~mm}$.

The FIA system comprised a Gilson Minipuls 3 peristaltic pump, fitted with PVC tubing (1.0-mm i.d.) and a four-way Rheodyne 5020 injection valve. The detection system was a Jenway 6300 single-beam spectrophotometer comprising a $100-\square \mathrm{L}$ flow- through cell and an optical path length of $10 \mathrm{~mm}$. PTFE tubing (Omnifit, Teflon, 0.8-mm i.d.) and Gilson end-fittings and connec- tors were used to connect all the components of the manifold. The output signals were recorded by means of a Ross 201 B 1596 recorder.

The $\mathrm{pH}$ of buffer solutions was determined with a Crison 2002 $\square \mathrm{pH}$ meter with a Sentek 71728 combined glass electrode.

\section{Reagents and solutions}

All chemicals were of analytical grade, and deionized water (conductivity $<0.1 \square \mathrm{S} \mathrm{cm}^{-1}$ ) was used.

Ascorbic acid, 4-amino antipyrine (AAP), boric acid, potassium hexacyanoferrate(III) (HCF), potassium chloride, sodium peroxodisulfate (PDS), sodium tetroxoiodate(VII) (TOI), gallic acid monohydrate $\left(\mathrm{GA} . \mathrm{H}_{2} \mathrm{O}\right)$, anhydrous sodium carbonate, ammonium sulfate, and tartaric acid were purchased from Riedel-de Haën; sodium hydroxide, glucose, sucrose, fructose, ethanol, and methanol were purchased from Merck; and Folin-Ciocalteu reagent was obtained from Fluka.

Buffer solutions of $\mathrm{pH} 10,11,12$, and 13 were prepared by addition of $0.1 \mathrm{~mol} \mathrm{~L}^{-1}$ aqueous boric acid solution to $0.12 \mathrm{~mol} \mathrm{~L}^{-1}$ aqueous sodium hydroxide solution until the desired $\mathrm{pH}$ was obtained. This procedure was followed by appropriated dilution, to furnish a final ionic strength of $0.01 \mathrm{~mol} \mathrm{~L}^{-1}$, and subsequent reevaluation of the final $\mathrm{pH}$. The $\mathrm{pH}$ meter was calibrated by means

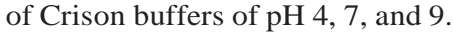

Gallic acid (GA) standard solutions were daily prepared in buffer by appropriate dilution of a mother solution. This last solution, usually $1850 \mathrm{mg} \mathrm{L}^{-1} \mathrm{GA}$, was prepared by accurate weighting of the corresponding solid and appropriate dilution with buffer.

Oxidizing agent solutions, $10 \mathrm{~g} \mathrm{~L}^{-1}$ in $\mathrm{HCF}$, PDS, or TOI, were usually prepared by dissolving approximately $1 \mathrm{~g}$ of the solid in a final volume of $100.00 \mathrm{~mL}$ buffer. AAP solutions were prepared in $100.00 \mathrm{~mL}$ of buffer by dissolution of the solid to a final concentration of $1.7 \mathrm{~g} \mathrm{~L}^{-1}$. Dilute solutions of oxidizing agents and AAP were obtained by appropriate dilution of mother solutions.

Interference from glucose, fructose, sucrose, tartaric acid, ascorbic acid, methanol, ammonium sulfate, and potassium chloride were evaluated for $185 \mathrm{mg} \mathrm{L}^{-1} \mathrm{GA}$ solutions in buffer prepared with or without the interfering compound at concentration levels of $185 \square 10^{-1}, 185$ and $185 \square 10^{1} \mathrm{mg} \mathrm{L}^{-1}$. The interference of ethanol was also evaluated, but for concentrations of 0.2, 2.0, and $20 \%(\mathrm{v} / \mathrm{v})$, keeping the concentration of GA constant.

\section{Procedures}

The appropriate oxidizing agent was selected under batch conditions by recording the absorption spectra, in the visible region, of $16.7,33.3,50.0,66.7$, and $83.3 \mathrm{mg} \mathrm{L}^{-1}$ gallic acid solutions containing oxidizing agent and AAP concentrations of 3.33 and $0.567 \mathrm{~g} \mathrm{~L}^{-1}$, respectively, in $\mathrm{pH} 11$ buffer.

The appropriate concentration ratio for the reagents was evaluated from the absorption spectra of solutions of GA $(2.25$, $2.25 \square 10^{1}$, or $2.25 \square 10^{2} \mathrm{mg} \mathrm{L}^{-1}$ ), oxidizing agent $\left(1.0,1.0 \square 10^{1}\right.$, or $\left.1.0 \square 10^{2} \mathrm{~g} \mathrm{~L}^{-1}\right)$, and AAP $\left(1.7 \square 10^{-1}, 1.7\right.$, or $\left.1.7 \square 10^{1} \mathrm{~g} \mathrm{~L}^{-1}\right)$ in dif-

ferent combinations. All solutions were here prepared in $\mathrm{pH} 11$ buffer.

To select the appropriate $\mathrm{pH}$ for formation of the colored complex, standard GA solutions of concentration 130, 195, and $260 \mathrm{mg}$ $\mathrm{L}^{-1}$ were prepared in buffer solutions of $\mathrm{pH} 10,12$, and 13 . For $\mathrm{pH}$ 11 more dilute solutions were used - concentrations 41.3, 62.0, and $82.7 \mathrm{mg} \mathrm{L}^{-1}$. All solutions contained the same concentrations of oxidizing agent and AAP -3.33 and $0.567 \mathrm{~g} \mathrm{~L}^{-1}$, respectively.

The evolution, with time, of the color intensity of the complex was determined by measuring the absorbance of 18.1, 36.2, and $54.3 \mathrm{mg} \mathrm{L}^{-1}$ standard solutions of GA, kept in daylight and at room temperature, at $30 \mathrm{~min}$ intervals for a maximum period of $2 \mathrm{~h}$. The stability of the complex over a period of $24 \mathrm{~h}$ was evaluated by measurement of the absorbance of the solutions the following day. The concentrations of oxidizing agent and AAP in these solutions were constant -3.33 and $0.567 \mathrm{~g} \mathrm{~L}^{-1}$, respectively.

Several characteristics of the FIA system depicted in Fig. 1 flow rate, injection volume, and reaction coil lengths - were optimized univariantly by producing calibration curves after analysis

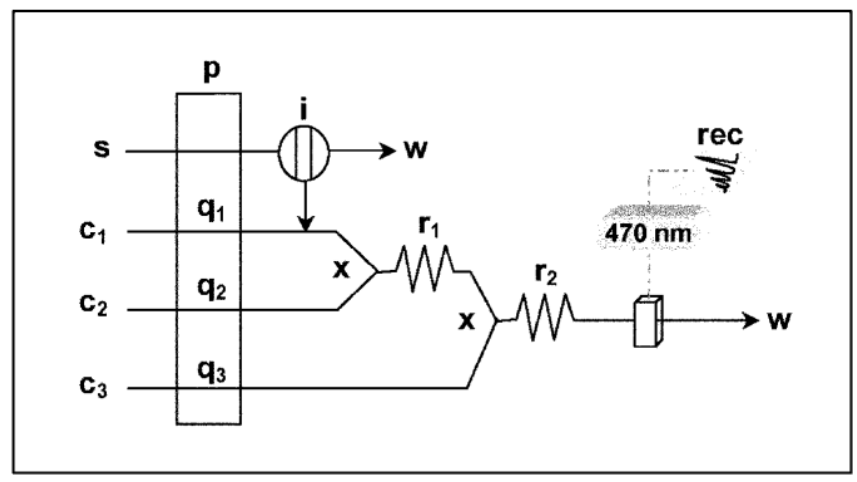

Fig. 1 Flow manifold diagram for determination of polyphenols in wines. $s$, sample; $c_{1}$, buffer carrier $\left(\mathrm{pH} \mathrm{11);} c_{2}\right.$, HCF solution $\left(9 \mathrm{~g} \mathrm{~L}^{-1}\right)$ carrier, prepared in buffer of $\mathrm{pH} 11 ; c_{3}$, AAP solution $\left(1.7 \mathrm{~g} \mathrm{~L}^{-1}\right)$ carrier, prepared in buffer of $\mathrm{pH} 11$; $p$, peristaltic pump; $q_{1}+q_{2}+q_{3}$, overall flow-rate of $1.5 \mathrm{~mL} \mathrm{~min}^{-1} ; i$, injection volume (500 $\square \mathrm{L}$ ); $x$, confluence points; $r_{1}$ and $r_{2}$, reaction coils of length 200 and $10 \mathrm{~cm}$, respectively; $w$, waste; rec, recorder of spectrophotometric readings at $470 \mathrm{~nm}$ 
of standard solutions of GA at concentrations between 50 and $250 \mathrm{mg} \mathrm{L}^{-1}$. The GA standard solutions were prepared in buffer $(\mathrm{pH} 11)$ and injected through the four-way injection valve (i, Fig. 1) into a carrier stream comprising the same buffer ( $c_{1}$, Fig. 1). The GA was made react first with $9.0 \mathrm{~g} \mathrm{~L}^{-1}$ oxidizing agent solution, propelled as carrier 2 ( $c_{2}$, Fig. 1), and afterwards mixed with AAP solution $\left(1.7 \mathrm{~g} \mathrm{~L}^{-1}\right)$, inserted into the system as carrier $3\left(\mathrm{c}_{3}\right.$, Fig. 1). These reactant solutions were prepared in buffer of $\mathrm{pH} 11$. To ensure proper development of the reaction inside the manifold, two reaction coils were placed in the FIA system $\left(r_{1}\right.$ and $r_{2}$, Fig. 1). Under the experimental conditions selected for FIA wine sam- ples were injected into the manifold after 10-fold dilution with pH 11 buffer.

Comparison method

Results from analysis of wines by the proposed method were compared with those obtained by use of the Folin-Ciocalteu method [8].

Sodium carbonate solution was prepared by dissolving the anhydrous salt $(200 \mathrm{~g})$ in boiling water $(800 \mathrm{~mL})$. The solution was seeded with a few crystals and filtered the next day. The volume was then adjusted to $1000 \mathrm{~mL}$ in a volumetric flask. A calibration set of GA standard solutions (concentration 0-250 $\mathrm{mg} \mathrm{L}^{-1}$ ) were prepared in water. Samples of red wine were diluted 10-fold with water. Each standard or sample $(1 \mathrm{~mL})$ was placed in a $100.00-\mathrm{mL}$ flask with water and the mixture was homogenized. After addition of Folin-Ciocalteu reagent the solutions obtained were mixed and diluted to volume with sodium carbonate solution after different periods from $30 \mathrm{~s}$ to $8 \mathrm{~min}$. The absorbance was read at $765 \mathrm{~nm}$ after storage of the solutions at $20^{\circ} \mathrm{C}$ for $2 \mathrm{~h}$.

Results and discussion

Batch trials

Because the formation of the colored complex of polyphenols in the presence of AAP depends on the presence of an oxidizing agent, several reagents were tested for this purpose, including HCF, PDS, and TOI. The visible spectra obtained from several GA standard solutions prepared with different oxidizing agents indicated that sensitivity (steeper slope) and repeatability were best when HCF was used - the molar extinction coefficient was 2667 \pm $133 \mathrm{~L} \mathrm{~mol}^{-1} \mathrm{~cm}^{-1}$ (Fig. 2A). For similar reaction times the sensitivity was 2.1 and 3.1 times higher than those recorded after use of PDS and TOI, respectively. To select other experimental conditions further studies, using a univariant process, were performed in the presence of $\mathrm{HCF}$.

To find the appropriate concentration ratio for the reagents several spectra were recorded for solutions prepared with significantly different concentrations of GA, AAP, and HCF. The highest concentrations of oxidizing agent and complexing agent led to severe precipitation; the lowest concentrations led to very low absorbance, even after extended periods of time. For a GA concentration of approximately $225 \mathrm{mg} \mathrm{L}^{-1}$ the highest absorbance readings were obtained at $470 \mathrm{~nm}$ and for standard solutions with AAP and HCF concentrations of 0.57 and $3.33 \mathrm{~g} \mathrm{~L}^{-1}$, respectively.

The effect of $\mathrm{pH}$ was evaluated at $\mathrm{pH} 10,11,12$ and 13; this range was selected because the reaction between phenol and HCF and AAP is usually better under alkaline
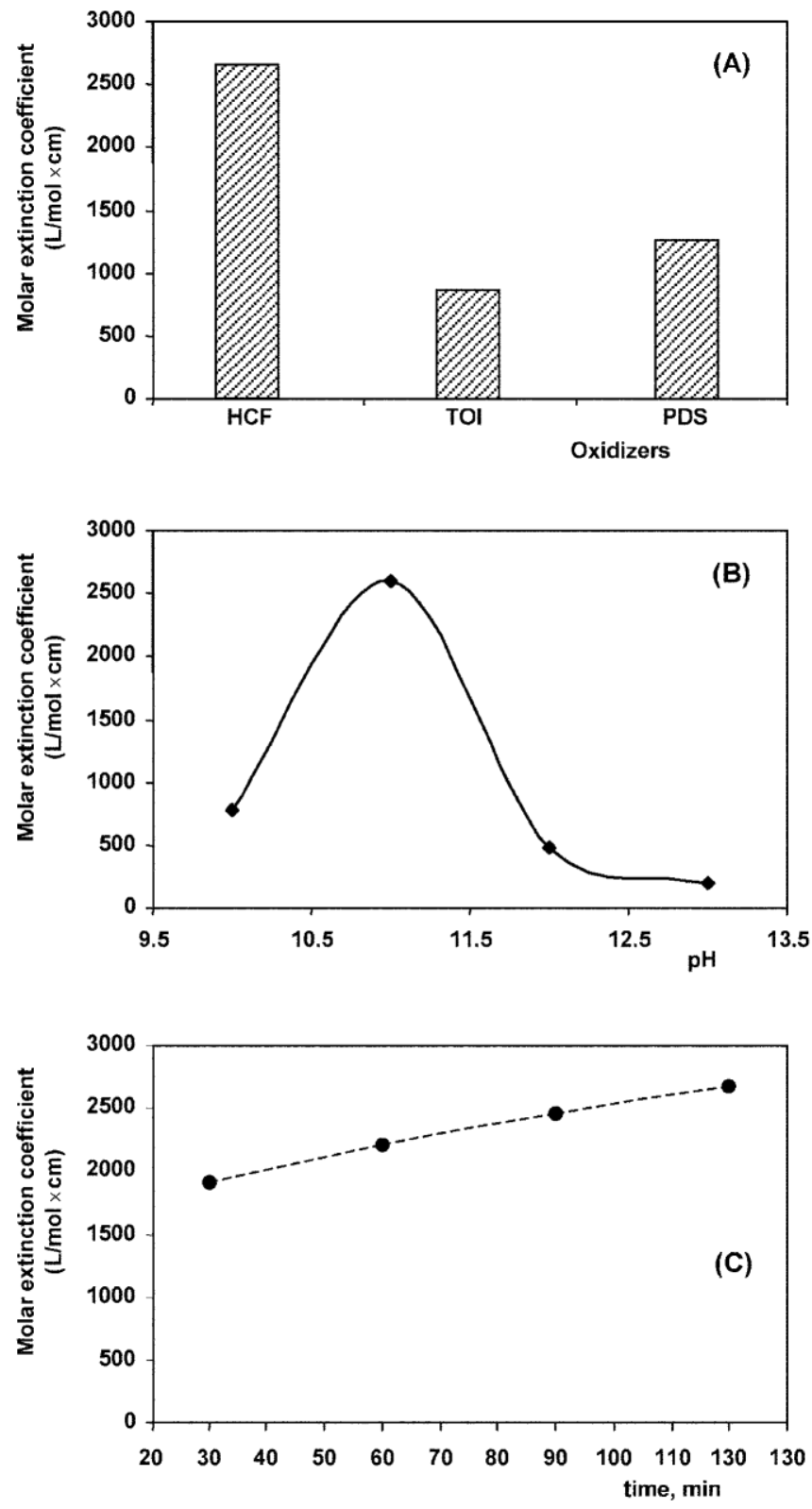

Fig. 2 Molar extinction coefficients for standard solutions of GA with (A) different oxidizing agents (HCF, TOI, and PDS) or (B) at different $\mathrm{pH}(10,11,12$, and 13$)$, or $(\mathbf{C})$ at different times $(30,60$, and $90 \mathrm{~min}$ )

solutions $[12,13]$. For calibration solutions maximum sensitivity was recorded at $\mathrm{pH} 11$, as is apparent from Fig. 2B.

Results from previous experiments were all recorded after the same amount of time, because it was readily apparent that the color of the solutions tended to increase for some time after mixing of the reagents. From calibration curves obtained by use of solutions prepared under the conditions already selected it was found that the highest sensitivity was achieved after a period of $2 \mathrm{~h}$ (Fig. 2C). After this time absorbance values decreased, falling by $80 \%$ in $24 \mathrm{~h}$. 

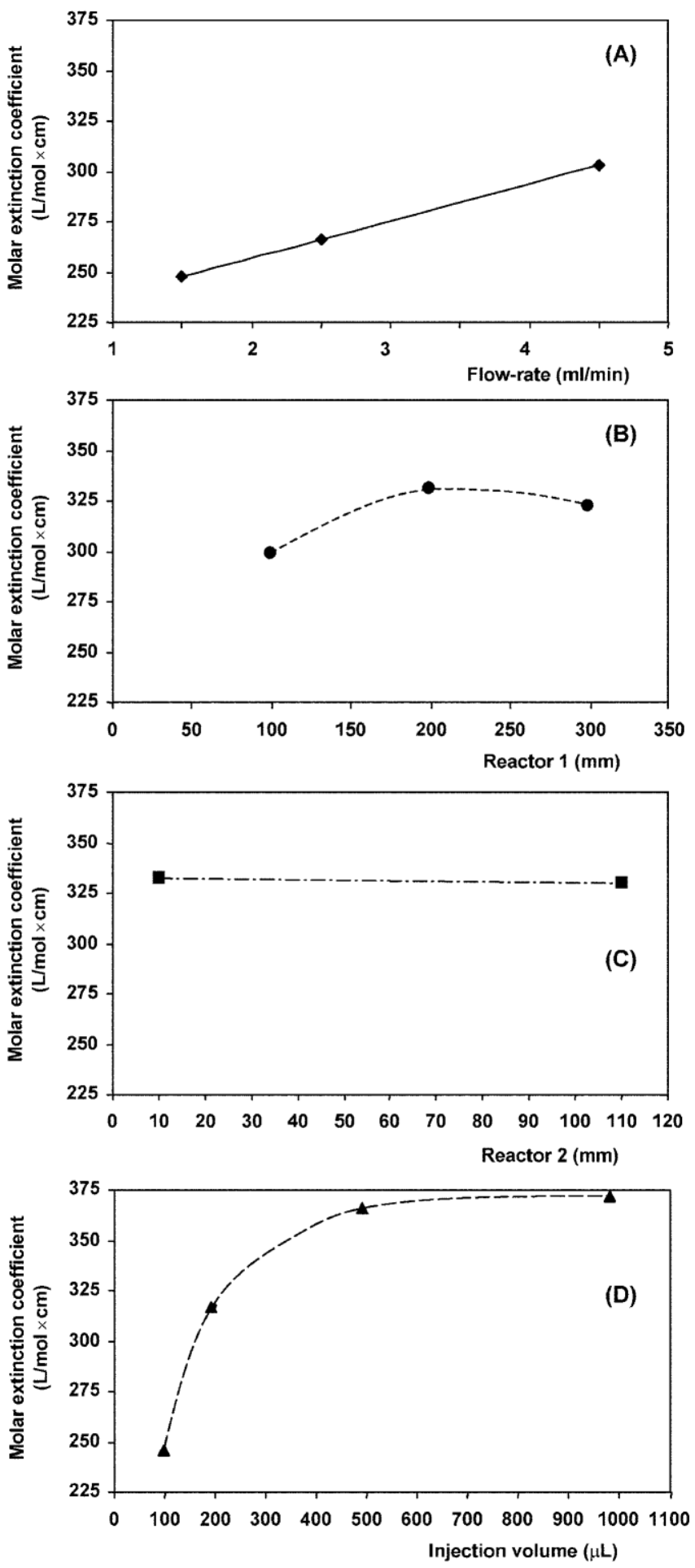

Fig. 3 Sensitivity of calibration curves from analysis of standard solutions of $\mathrm{GA}$ at concentrations from 49.7 to $362.4 \mathrm{mg} \mathrm{L}^{-1}$ recorded under different conditions: (A) different flow-rates; (B) reactor $1\left(r_{1}\right.$, Fig. 1$)$ of different lengths; (C) reactor $2\left(r_{2}\right.$, Fig. 1$)$ of different lengths; (D) different injection volumes

Flow trials

The conditions selected on the basis of results from the batch experiments were implemented for optimization of the FIA manifold. All solutions were prepared in carrier buffer of $\mathrm{pH}$ 11. The GA standard solution was reacted first with the oxidizing agent by means of a confluence point with the corresponding carrier solution (Fig. 1). Because this carrier solution would be diluted approximately fourfold during passage through the system, to ensure the amount of reagent necessary for reaction to occur properly, without precipitation, the concentration selected was $9.0 \mathrm{~g} \mathrm{~L}^{-1}$, three times that obtained from batch trials. The GA and oxidizing agent in this plug was then reacted with AAP by confluence with the proper carrier. The concentration of the AAP solution inserted into the system was $1.7 \mathrm{~g} \mathrm{~L}^{-1}$, three times of that selected from batch experiments. To ensure adequate reaction times inside the manifold, two reaction coils, $r_{1}$ and $r_{2}$, length 100 and $10 \mathrm{~cm}$, respectively (Fig. 1), were placed after the confluence points.

With the FIA manifold operating under these conditions the effect of several other conditions was studied by use of a univariant process and comparison of the sensitivity of calibration curves obtained by analysis of GA standard solutions within the concentration range 49.7 to $362.4 \mathrm{mg} \mathrm{L}^{-1}$.

The flow-rate was varied from 1.5 to $4.5 \mathrm{~mL} \mathrm{~min}{ }^{-1}$ and, unexpectedly, increasing the flow rate led to increased sensitivity (Fig. 3A). The sampling rate could be increased to approximately 100 samples per hour. Because $4.5 \mathrm{~mL} \mathrm{~min}^{-1}$ could be too high for spectrophotometric determination, and because of possible differences between the kinetics of the reaction for standards and real matrices, it was decided that this condition would be reevaluated when all the other conditions had been optimized. In subsequent experiments a value of either 2.5 or

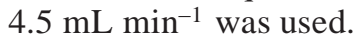

The length of the first reaction coil ( $\mathrm{r}_{1}$, Fig. 1) was varied from 100 to $300 \mathrm{~cm}$. The calibration curves obtained indicated that the sensitivity increased with increasing coil length until the length was $200 \mathrm{~cm}$, after which sensitivity started decreasing (Fig. 3B), presumably as a result of augmenting both the extent of the reaction and dispersion. With the first reactor set to $200 \mathrm{~cm}$ the length of the second was tested for 10 and $110 \mathrm{~cm}$. In contrast with results obtained for $r_{1}$, increasing the length of $r_{2}$ led to a small decrease in sensitivity (Fig. 3C). It seems that complexation with AAP to form the colored complex occurs very quickly and that increasing the length of this reactor results in a dilution effect.

Under the conditions already selected the injection volume was varied from 100 to $1000 \square \mathrm{L}$. As expected, increasing the injection volume led to a significant increase in sensitivity, more perceptible for low injection volumes (Fig. 3D). Because the rate of increase was very small for volumes between 500 and $1000 \square \mathrm{L}$, the latter was selected; this lower sampling volume also enabled higher sampling rates.

After optimization of these conditions the response of the proposed FIA procedure was linear within the range $36-544 \mathrm{mg} \mathrm{L}^{-1}$, with a slope of $338.5 \pm 8.6 \mathrm{~L} \mathrm{~mol}^{-1} \mathrm{~cm}^{-1}$, an intercept of $0.018 \pm 0.006$, and an $\mathrm{R}^{2}>0.9992$. Because 
Table 1 Absorbance readings obtained from standard solutions of $185 \mathrm{mg} \mathrm{L}^{-1} \mathrm{GA}$ prepared without or with a possible interfering compound at a level 10,100 , or $1000 \%$ that of GA

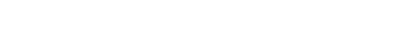

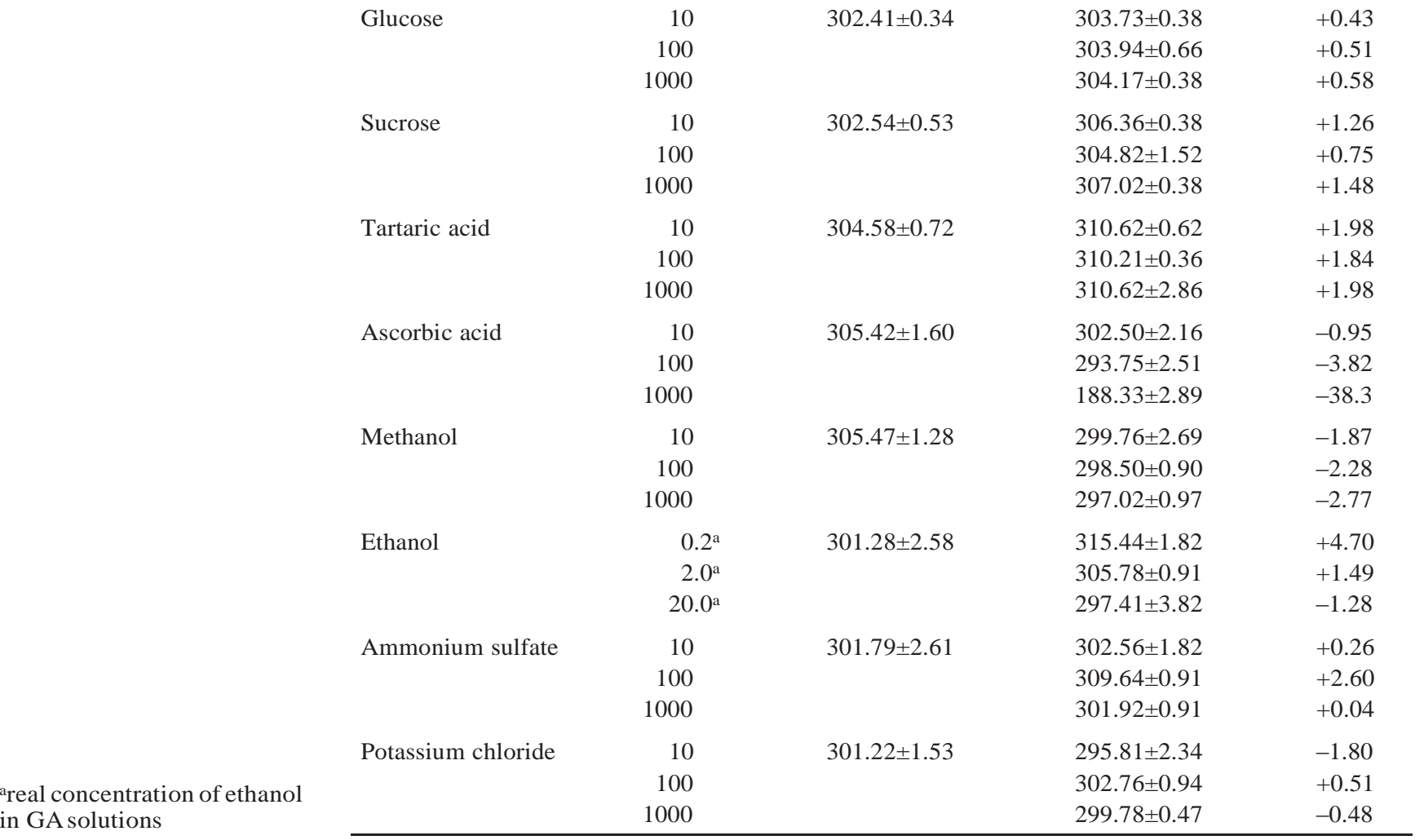

the flow-rate used to obtain these results was $4.5 \mathrm{~mL} \mathrm{~min}^{-1}$, which might still be too high for analysis of wines, trials were performed on real samples. It was found that for these matrixes the kinetics were slower, and prevented the use of the high flow-rate. Calibrations were therefore,

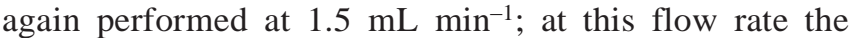
slope was $344.0 \pm 10.45 \mathrm{~L} \mathrm{~mol} \mathrm{~cm}^{-1}$, the intercept $0.013 \pm 0.010$, and $\mathrm{R}^{2}>0.9996$. Although this behavior was the opposite of that observed during the first optimization of the flow-rate, it was much closer to the behavior expected, not just because of the lower dispersion of the solutions but also because of the longer time available for reaction to occur. Under these conditions the reproducibility of analytical readings, determined on different days with different solutions and with the same equipment, was $1.01 \%$ for a $135.2 \mathrm{mg} \mathrm{L}^{-1}$ standard solution of GA.

Interference from several compounds usually present in wines was evaluated by examining differences between absorbance readings obtained from GA standard solutions prepared with or without the interfering compound. For reducing or non-reducing sugars no interference was detected, as is apparent from Table 1. Tartaric acid, ethanol, methanol, and inorganic ions were also found not to interfere with FIA determination of GA.
Ascorbic acid, a natural component of grapes that disappears during the vinification process but which can be found in wines because of its addition, during processing, to prevent oxidation, did interfere. This interference was, however, perceptible only at a concentration of $1850 \mathrm{mg}$ $\mathrm{L}^{-1}$; it was negligible at $185 \mathrm{mg} \mathrm{L}^{-1}$ (Table 1). Because addition of ascorbic acid is legally limited to a maximum concentration of $150 \mathrm{mg} \mathrm{L}^{-1}$ in Europe [1], interference of this compound with the determination of polyphenols in wines can be regarded as negligible.

Addition of free $\mathrm{SO}_{2}$ to wines, to a maximum concentration of $30 \mathrm{mg} \mathrm{L}^{-1}$, is an alternative to addition of ascorbic acid. Because both ascorbic acid and $\mathrm{SO}_{2}$ are used for the same chemical purpose, and bearing in mind that ascorbic acid did not interfere at the maximum concentration permitted by law, interference by $\mathrm{SO}_{2}$ was here not expected. Previous work on adaptation of the FolinCiocalteu method to FIA [10] indicated tolerance to $400 \mathrm{mg} \mathrm{L}^{-1} \mathrm{SO}_{2}$ and to $50 \mathrm{mg} \mathrm{L}^{-1}$ ascorbic acid, suggesting that interference from the latter compound was much higher. The classical Folin-Ciocalteu method is more prone to interference from $\mathrm{SO}_{2}$ [11] than the FIA method, possibly because working under stationary conditions enables the reaction to proceed further. To be certain of this 
Table 2 Determination of total polyphenols in wines by use of the proposed FIA method and by the Folin-Ciocalteu method, with the corresponding relative error (RE) and F-test value

\begin{tabular}{lcccc}
\hline Sample & \multicolumn{2}{l}{ Total polyphenols (expressed GA, mg L $\left.{ }^{-1}\right)$} & \multirow{2}{*}{ RE (\%) } & \multirow{2}{*}{ F test } \\
\cline { 2 - 3 } & \multicolumn{1}{c}{ FIA } & Folin-Ciocalteu & & \\
\hline Red wine 1 & $979.8 \pm 36.5$ & $937.5 \pm 17.0$ & +4.52 & 0.22 \\
Red wine 2 & $1363.4 \pm 32.1$ & $1310.1 \pm 43.7$ & +4.07 & 1.85 \\
Red wine 3 & $1644.6 \pm 40.6$ & $1626.5 \pm 31.0$ & +1.11 & 0.58 \\
Red wine 4 & $1787.0 \pm 60.9$ & $1820.5 \pm 56.2$ & -2.19 & 0.85 \\
Red wine 5 & $1451.5 \pm 55.2$ & $1381.5 \pm 27.4$ & +5.06 & 0.25 \\
\hline
\end{tabular}

non-interference from $\mathrm{SO}_{2}$ at the levels permitted by law, a $100 \mathrm{mg} \mathrm{L}^{-1}$ standard solution of GA containing $100 \mathrm{mg} \mathrm{L}^{-1}$ of $\mathrm{SO}_{2}$ was prepared. Absorbance readings for this solution were similar to those for a pure GA standard solution of $100 \mathrm{mg} \mathrm{L}^{-1}$; the relative error, $-0.74 \%$, was indicative of negligible interference from $\mathrm{SO}_{2}$.

Analysis of wine samples

Total polyphenols were determined spectrophotometrically in wines after calibrating the FIA system under the optimized conditions. Before injection every sample was diluted tenfold, to fit the calibration curve. Results obtained for several red wines are listed in Table 2 as averages and standard deviations for six independent determinations. Sampling rates were about 55 samples $\mathrm{h}^{-1}$ when real samples were injected (Fig. 4) and results were precise - the maximum RSD was $3.8 \%$ (Table 2).

The accuracy of FIA results was apparent from relative deviations $<5 \%$ when results were compared with those

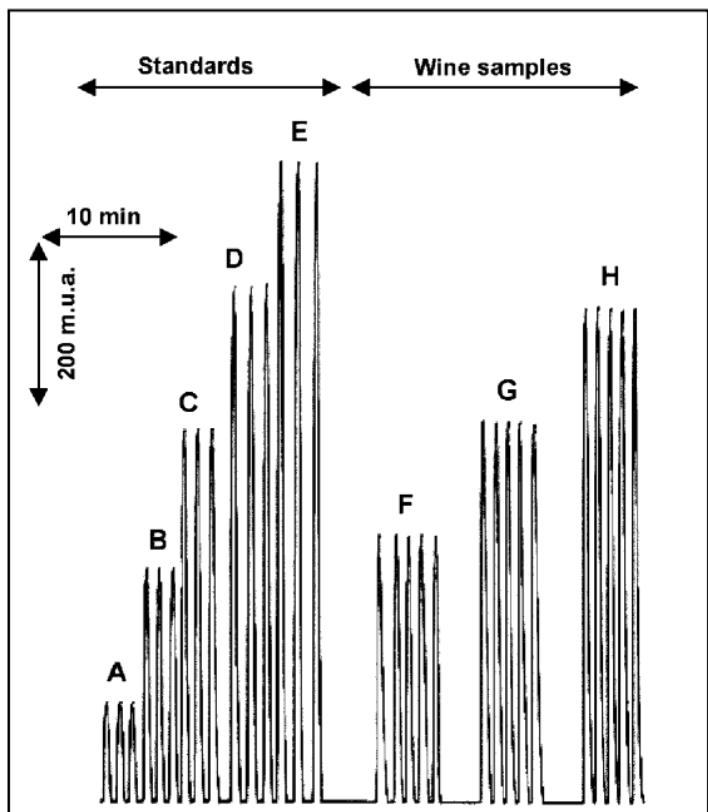

Fig. 4-Record of response from stand solutions of $G A$ at concentrations of $45.8,91.7,137.5,183.3$, and $229.1 \mathrm{mg} \mathrm{L}^{-1}$, and wine real samples (numbers 1 and 2 in Table 2 and another not included there) diluted 10 times from the Folin-Ciocalteu method. Also, considering as null hypothesis that the two methods agree, a paired twotail test for $5 \%$ level of significance gave a calculated $t$ $(0.170)$ below that tabulated $\left(\mathrm{t}_{0.05,10}=1.812\right)$, confirming the null hypothesis. Variances obtained for each sample were compared by use of the F-test, using the same assumptions as for the Student t-test; the calculated values (Table 2) were always less than the critical F-value $\left(\mathrm{F}_{0.025(5,5)}=7.15\right)$, thus confirming the null hypothesis.

Two other wine samples, not indicated in Table 2, were analyzed both by the proposed method and by the FolinCiocalteu procedure. The results obtained from the two methods were different; it was assumed this was because interference from $\mathrm{SO}_{2}$ was more probable at the comparison method than at the here proposed one. Substantial interference of $\mathrm{SO}_{2}$ with the Folin-Ciocalteu method has been reported in the literature [11]. Although the level of $\mathrm{SO}_{2}$ in those samples was unusually high (>100 mg L L ${ }^{-1}$, the possibility of interference with the proposed procedure cannot be neglected.

\section{Conclusions}

Batch and FIA experiments were used to optimize the sensitivity of the analysis. The interference of several compounds commonly present in wines seems to be negligible; this is a significant achievement considering the substantial interferences suffered by the comparison method.

The accuracy of results obtained by use of the proposed method seems good, in particular because errors relative to those obtained by use of the Folin-Ciocalteu method were below $5 \%$ for most samples. Results for two sample wines were outside this range, possibly because of interference of $\mathrm{SO}_{2}$ with the proposed procedure, if the $\mathrm{SO}_{2}$ content of the samples was $>100 \mathrm{mg} \mathrm{L}^{-1}$, or with the reference method. Correction factors for the latter method are given in the literature [11], suggesting very high interference from this compound and implying, as a consequence, the need to determine total sulfur dioxide so that total polyphenols can be estimated.

It seems, therefore, that the procedure proposed in this paper could be an alternative to routine determination of polyphenols in wines. The FIA system is simple, inexpensive in terms of reagent consumption and equipment involved, and enables analysis of approximately 55 samples $\mathrm{h}^{-1}$. Sample preparation is simple dilution with buffer; this 
could be avoided by addition of another channel to the FIA manifold, a procedure which would not lead to dilution problems, because of the wide linear concentration range and because of the high concentration of polyphenols in wines.

\section{References}

1. Curvelo-Garcia AS (1988) Controlo de qualidade dos vinhos, Química enológica - Métodos analíticos. Instituto da vinha e do vinho, Lisbon

2. Brenna O, Buratti S, Cosio MS, Mannino S (1998) Electroanalysis 10:1204-1207

3. Rechner A, Patz CD, Dietrich H (1998) Dtsch Lebensm Rundsch 94:360-365
4. Guillen DA, Barroso CG, Bustamante JAP (1996) J Chromatogr A 724:117-124

5. Barroso CG, Cela R, Bustamante JAP (1986) An Bromatol 37:143-152

6. Jerumanis J (1973) Bull Anc Et Brasserie Louvain 69:1-14

7. Buitrago J, Cela R, Bustamante JAP (1986) Afinidad 43: 530-536

8. Singleton VL, Rossi JL Jr (1965) Am J Enol Vitic 16:144-158

9. Tortajada MP, Cerrada MP, Maquieira A (1989) Quim Anal 8: 211-222

10. Celeste M, Tomas C, Cladera A, Estela JM, Cerda V (1992) Anal Chim Acta 269:21-28

11. Ough CS, Amerine MA (1988) Methods for analysis of musts and wines, 2nd edn. Wiley, New York

12. Liu LZ, Gu T, Li FX, Shen HX (1996) Fenxi Shiyanshi 15:4-7

13. Kobenmam YAI, Ermolaeva TN, Kuchmenko TA, Mishina AV (1993) Zh Prikl Khim 66:2043-2047 